Running head: Red Listing in Central Asia

\title{
Application of IUCN red listing criteria at the regional and national levels:
}

\section{A case study from Central Asia}

Milner-Gulland, E.J. ${ }^{1 *}$, Kreuzberg-Mukhina, E. ${ }^{2}$, Grebot, B. ${ }^{1}$, Ling, S. ${ }^{1}$, Bykova, E. ${ }^{2}$, Abdusalamov, I. ${ }^{3}$, Bekenov, A. , Gärdenfors, U. ${ }^{5}$, Hilton-Taylor, C. ${ }^{6}$, Salnikov, V. ${ }^{7}$, Stogova, L. $^{8}$

CITATION: Milner-Gulland, E.J., Kreuzberg-Mukhina, E., Grebot, B., Ling, S., Bykova, E., Abdusalamov, I., Bekenov, A., Gärdenfors, U., Hilton-Taylor, C., Salnikov, V., Stogova, L. (in press) Application of IUCN red listing criteria at the regional and national levels:A case study from Central Asia. Biodiversity and Conservation

* Corresponding author. Imperial College London, Silwood Park Campus, Manor House, Buckhurst Road, Ascot, Berks, SG5 7PY, UK. Tel: 0207594 2509. Fax: 0207594 2513. Email: e.j.milner-gulland@imperial.ac.uk.

1. Imperial College London, UK. 2. Institute of Zoology, Uzbekistan. 3. Institute of Zoology \& Parasitology, Tadjikistan. 4. Institute of Zoology, Kazakhstan. 5. Swedish Species Information Centre, Uppsala. 6. IUCN-SSC, Cambridge, UK. 7. National Institute of Deserts, Flora and Fauna, Turkmenistan. 8. Institute of Botany and Phytointroduction, Kazakhstan. 


\begin{abstract}
We assessed the threatened status of 163 Central Asian vertebrates using the IUCN Red List Criteria (Version 3.1) at the national and regional levels, and compared these assessments to the global assessments given in the IUCN 2002 Red List. We thus compared threat status at 3 spatial scales; national for 5 countries separately (Kazakhstan, Kyrgyzstan, Tadjikistan, Turkmenistan, Uzbekistan), regional for the 5 countries together, and global. This analysis was undertaken as a test of the applicability of IUCN criteria at the sub-global level. Generally the criteria worked well. In $4 \%$ of cases, the threat category was lower at the smaller scale of assessment. This was predominately caused by the use of decline rate criteria at the larger scale when populations at the smaller scale were stable. We also encountered issues with the listing of migratory species at the sub-global level. We used our data to carry out a preliminary assessment of Protected Area coverage in the region, and found evidence suggesting that threatened species and endemics are not well covered by the current protected area system.
\end{abstract}

Key words: Kazakhstan, Kyrgyzstan, Protected area coverage, Tadjikistan, Threatened species, Turkmenistan, Uzbekistan. 


\section{Introduction}

Red listing is the process of assigning species to a category of threat representing their risk of extinction. IUCN (the World Conservation Union) first started red listing in the early 1960s, but there was a significant change in 1994 when new, more quantitative criteria were used for the first time (IUCN 1994). Since then, there has been an upsurge of interest in the IUCN red listing process, and in particular in applying IUCN's Red List criteria at the national level. In response, IUCN has published guidelines for the application of the IUCN Red List criteria at sub-global levels (Gärdenfors et al. 2001; IUCN 2003). However, to date there has been limited testing of these guidelines (Gärdenfors 2001), and no published studies are available comparing listings done for the same species at national, regional and global levels.

In this paper we examine the effect of scale on the outcome of red listing for a range of species of varying threat status, endemicity, taxonomic group and life history. The study involves five Central Asian countries: Kazakhstan, Kyrgyzstan, Tadjikistan, Turkmenistan, and Uzbekistan, allowing us to look at Red List status at three nested levels; national, regional (all 5 countries together) and global. We also relate the coverage of Central Asia's protected areas to the threat status of the assessed species. Central Asia is a particularly good location for this kind of study, as it is a geographically diverse region, has a high degree of endemicity at both national and regional levels and has been relatively isolated from the post1994 upsurge in red listing efforts until now. This is the first time that the new IUCN Red List Criteria have been used by scientists in the region to assess the status of a large number of species at the national and regional levels.

Despite its isolation from the recent IUCN Red List process, the former Soviet Union has a long history of red listing activity and engagement with IUCN. The first Red Data Book 
(RDB) for the USSR was published in 1978, at the same time as the first Red Data Book of Kazakhstan (Sludsky 1978; Kovshar' et al. 1996). In the countries of the former Soviet Union, Red Data Books (RDBs) are government-endorsed documents, and as such, have major significance for their countries' conservation policy. All the Soviet Republics produced their own RDBs, but the criteria by which species were listed varied between republics, making any comparison between them extremely difficult. The process of producing RDBs at the USSR level was disengaged from within-Republic processes, and regional-level RDBs were not compiled. Hence our study is the first to produce assessments of species' threat status for the ex-Soviet Central Asian region as a whole.

\section{Methods}

A list of 163 vertebrate species and subspecies was drawn up, with the intention of representing a range of taxonomic groups, life histories, endemicity, perceived threat status and knowledge about the taxon. All these species or subspecies were included previously in at least one national RDB in the region. We were explicitly not aiming for a representative sample of Central Asia's vertebrate fauna. Instead, the aim behind our choice of species was to test the IUCN regional application guidelines as rigorously as possible by applying them in a wide range of situations, given the time and budgetary constraints that we faced. The sample consisted of 13 fish taxa (species and subspecies), 33 reptiles, 54 mammals and 63 birds There were 37 national or regional endemics in the sample.

Specialists in each of the five participating countries filled in a detailed questionnaire requesting information about the life history, ecology, conservation status, population and range area trends of these species/sub-species within their country. No new data were gathered for the study; instead expert knowledge and literature searches were used. The data 
requested included all the information required to make an assessment of Red List status using any of IUCN's five sets of criteria (IUCN 2001). The specialists also reported on the presence of the species in protected areas in their country through the year, and their level of confidence in the presence/absence assessment. The range area data were included in a Geographical Information System (GIS) developed by the Institute of Botany and Phytointroduction, Kazakhstan. This GIS included information on species' past and current distributions, ecosystem type and the location of Protected Areas (PAs). Detailed data were available for 85 of the 163 taxa; this sub-sample of the dataset was used in an analysis of the coverage of the protected area system. Unfortunately, there were no data from Kyrgyzstan available for this analysis, so it was conducted only for the 4 other participating countries.

Using these data provided by the country experts, we assessed the threat status of each species/sub-species at the national and regional levels using version 3.1 of the IUCN Red List Categories and Criteria (IUCN 2001). Global status was taken from the 2002 IUCN Red List of Threatened Species (downloaded from www.redlist.org on 11 July 2003). In addition the IUCN Red List Programme office (through C. Hilton-Taylor) provided status information for the Least Concern (LR/lc) and Not Evaluated (NE) taxa. The data used to assess the global status of these taxa for the IUCN Red List were not available to us, and the specialists involved in our study had not been involved in the global red listing exercise. Hence it is unclear to what extent information from Central Asia was used to list species on the global IUCN Red List. The 2002 Red List is a compilation of Red List assessments made since 1995 using the 1994 and 2001 versions of the IUCN Red List Categories and Criteria (versions 2.3 and 3.1; IUCN 1994, 2001; see www.redlist.org for details). As most of the global listings were done in 1995 or 1996, a number of these are likely to be out-dated and/or inaccurate, and this should be borne in mind when examining the results of this study. National RDB 
threat status was taken from the most recent national RDBs, which varied in publication date from 1985 (Kyrgyzstan) to 2003 (Uzbekistan).

We assessed threat status at the national and regional levels using IUCN's guidelines (version 3.0, IUCN 2003). Uncertainty and decline rate data were also treated according to IUCN guidelines. These IUCN guidelines include a Not Applicable (NA) category for vagrants or recent introductions and the possibility of downgrading non-breeding visitors if conditions both within and outside the area of assessment are not deteriorating. The guidelines suggest that regional assessors have several options on how to decide the boundaries between visitors and vagrants, e.g., a preset percent of global share or predictability. We also assessed only breeding populations rather than non-breeding visitor populations of migratory species (all of which were birds).

Apart from the complications involved in defining the unit of assessment for migratory species, the main issue when assessing threat status at the sub-global level is the possibility that the sub-global assessment over-estimates extinction risk. IUCN (2003) suggests that this should be tackled by using the global criteria and then downgrading the listing if it is clear that extinction risk within the area of assessment has been over-estimated. For example, extinction risk within a country would be over-estimated if it contained only a very small proportion of a large healthy population. Although many of the taxa assessed in our study could have qualified for downgrading in theory, a precautionary approach was taken in view of the uncertain conservation situation in the region as a whole. Hence no assessments were downgraded. 
We assessed the effectiveness of the region's protected areas for the taxa in our sub-sample by comparing the threatened status of the taxa with their presence in protected areas. We used our regional assessment of threat status as the most accurate reflection of a taxon's current extinction risk in the region. The measure of PA coverage used was whether a taxon was definitely found in at least one PA at any time of the year. Only positive records were used in the analyses and hence absences are not distinguished from lack of data.

\section{Results and Discussion}

\section{Data used for listing}

Data quality and availability for the regional and national assessments varied between taxonomic groups, as did the degree of national and international interest in the taxon, as reflected by their appearance on the global IUCN Red List (Table 1) or in national RDBs. Despite the variability in data availability, the proportion of assessments that could not be carried out (giving rise to a Data Deficient listing) was low, and was fairly similar between taxonomic groups, reflecting the flexibility of the Red List Criteria in the face of poor data.

As might be expected, the region's birds and mammals were most likely to have been listed internationally, and also to have high quality data available. For birds, this is partly because Central Asia is an important area for migratory species moving between Africa and Asia. The taxonomic groups most lacking in international attention and in good quality regional data are fish and reptiles. This is partly because the region has significant diversity of endemic taxa within both groups. The prevalence of regional and national endemics in these taxonomic groups has also impacted the previous availability of data on these taxa to the international community. The main reason for taxa not having been evaluated at the global level is that the dataset includes a high proportion of subspecies. The IUCN Red List focuses primarily on 
species. However the pattern still holds when sub-species are removed (6/8 fish species assessed at the global level, 2/13 reptiles, 46/46 birds, 29/30 mammals). Although fish of the Aral Sea basin are well represented at the global level due to the ecological disaster of the Aral Sea (Jones 2003), other fish species (such as mountain endemics) have not received similar attention.

The criteria used to list species as threatened are reflective to some extent of the data available at each scale, as well as of the main threats to the species. Hence it is interesting to note the dramatic differences between the criteria used; at the global level, criterion A (decline rate) was the main one used, whereas at national and regional levels, criteria $\mathrm{B}$ and $\mathrm{C}$ (combinations of restricted range area or small population size and other threats) were most used (Fig. 1). Not surprisingly, small population size alone was more often used at the smallest geographical scale than at larger scales. As in many previous studies, criterion $\mathrm{E}$ (quantitative analysis) was not used at all.

Overall, $34 \%$ of the taxa in our study had not been evaluated at the global level. Of those that had been assessed, the spread of listings was relatively even, reflecting our sample selection strategy. The spread of listings was more skewed towards the threatened categories at subglobal level; $28 \%$ of the species assessed were threatened or extinct at the global level, $58 \%$ at the regional level and $61 \%$ at the national level (Fig. 2). Given that our sample was purposive rather than representative, it is not surprising that the proportion of species threatened at the national level was very much higher than that reported in previous studies (e.g. 22\% in Pinchera \& Boitani 1997, 8-10\% in Gärdenfors 2001). A caveat to this is that the extremely high proportion of fish taxa threatened or extinct in our study is likely to be a true reflection of the generally precarious status of the region's fish species. 


\section{Scale-dependent changes in listing}

It would broadly be expected that the smaller the area of assessment, the higher the threat status, given that a smaller area implies a smaller population size and a higher chance of meeting red listing criteria. This is generally the case in our study, particularly when comparing national with global listings (Fig. 3). Because of the high proportion of endemics within our sample, many of the listings remained the same at all spatial scales. In a few cases, species were assessed as less threatened at smaller spatial scales. Overall, $4 \%$ of the comparisons (32 of 758 comparisons) gave a lower threat status at the smaller scale of assessment, compared to $40 \%$ equal and $56 \%$ higher at the smaller scale.

It seems implausible that the threat status of a species should improve when it is assessed at a lower spatial scale. Compared to other studies, $4 \%$ of cases is a relatively low proportion; for example Gärdenfors (2001) found that $32 \%$ of species evaluated for Sweden's Red List were given a lower threat status in Sweden than globally. However, in order to evaluate the robustness of the IUCN system to scale effects, we need to examine these cases particularly closely.

There are two main reasons why lower threat statuses are recorded at the smaller scale; the use of decline rates in the assessment, and differences in interpretation between experts. Nineteen of the 32 cases recorded involved the use of criterion A at the higher level. Eight cases involved the use of criterion $\mathrm{C}$, which also requires the population to be declining. It is perfectly feasible for a species to be declining globally but remain stable within a country or region. In this situation, criteria $\mathrm{A}$ and $\mathrm{C}$ cannot be used at the smaller scale, and so the threat assessment is likely to be lower. The root cause of the discrepancies is that global threat 
assessments cannot take spatial sub-structuring into account (Collar et al. 1994). Extinction risk would generally be expected to be higher when a species is declining steadily across its range than when it is stable in parts of its range and declining dramatically in others. Globalscale assessments cannot take these differences into account.

Seventeen cases involved the use of the categories NT or LC, and three involved the use of VU D1. These categories are not quantitatively defined, hence differences in assessments are likely to be due to differences in assessors' perceptions of threat status. This does not imply that the quantitative categories of threat are scale-dependent. There is one taxon for which the populations under assessment differed; only the Aral Sea population of the Ship sturgeon (Acipenser nudiventris) is assessed at the global level. A population remains in the Amu Darya river in Turkmenistan and Uzbekistan, hence the CR listing for Turkmenistan, Uzbekistan and regionally contrasts with the EX listing at the global level and in Kazakhstan. There are introduced populations of this species in Kazakhstan which are Not Evaluated, because they are not within the historic range of the species.

\section{National Red Data Books}

A comparison of the national listings carried out in this study and the presence of taxa on national Red Data Books (RDBs) is useful for cross-validation of listing methods, given that all the RDBs were produced independently using different, predominately subjective listing criteria. This comparison could only be carried out for the 85 taxa for which there was detailed information. Broadly, the proportion of the sample listed in national RDBs is the same as the proportion assessed as Regionally Extinct to Near Threatened in our study (Fig 4). Given that the timescale over which the RDB assessments were published is from the mid-1980s (Kyrgyzstan and Tadjikistan) to the late 1990s (Turkmenistan and Kazakhstan) to 
the present day (Uzbekistan), there is an impressive level of concordance. This implies that by adopting the quantitative criteria of IUCN, these countries will not see a significant change in the number of species listed on their national RDBs.

At a finer scale the majority of the RDB assessments of threatened status differ from those made using the IUCN criteria. Thirty three percent of the species/subspecies were assigned lower threat categories in the national RDBs than were assigned using the IUCN system, $46 \%$ a comparable category and $21 \%$ a higher category. There were no significant differences between countries in their tendency to assign higher or lower categories of threat than the IUCN system, and given the age of the majority of the RDBs there is little to be gained from exploring the reasons behind these discrepancies in detail.

\section{Adequacy of Protected Area network}

This analysis used the sub-set of 85 taxa for which detailed information was available. Presence in a PA was significantly related to national threat status; Least Concern species were significantly more likely to be confirmed in a PA than threatened and near-threatened species (Table 2). Data Deficient species were significantly less likely to be in a PA than other species. This is not surprising, as we would expect that the majority of the field data used to make threat assessments comes from well-studied areas, which are most likely to be PAs. Also if species are inconspicuous, they are likely both to be missed from PA occurrence records and difficult to assess for their threat status.

Comparing between taxonomic groups, birds are particularly well represented within the PA system, and reptiles particularly badly (Table 2). It may seem surprising that birds are better represented than mammals. One reason for this can be seen by comparing the representation 
of commonly-hunted species with those that are not hunted. The "Hunted" category comprises all large mammals and smaller species which are commonly targeted, such as waterfowl and galliforms. In the sample, hunted species are far better represented in PAs. This suggests that whilst large mammals are well represented, small mammals do not necessarily fare any better than other less conspicuous groups. Virtually all the birds included in the sample were large waterbirds, hence the sample is heavily biassed towards hunted species.

Results with respect to habitat type are obscured by the coarseness of the classification; species were categorized as being primarily associated with aquatic/near-water, lowland (desert or arid species) or mountain habitats. Although lowland species not associated with water appeared to receive poorer coverage from the PA system, the chi-square value was narrowly non-significant. Endemic species are of particular concern in prioritising protected area coverage. It would be expected that endemics should occur in fewer areas than other species, because of their intrinsically smaller range sizes. However, our analysis is of concern as it shows that endemic species are significantly less likely to appear in even a single PA than other species.

It must be borne in mind that the explanatory variables we have used are highly confounded; For example, the mammals and birds in the sample are generally large-bodied, and targeted by hunters, and not so commonly associated with arid habitats as reptiles. Although only $27 \%$ of the sample are fish or reptiles, 15 of the 27 national or regional endemics analysed are from these two groups. The analyses should not be viewed as independent, therefore; essentially they are different ways of phrasing the same thing. Despite the limitations, the central message is clear; in our sample, large-bodied birds and mammals, which coincide 
with those species most noticeable to and preyed upon by humans, are better represented within the PAs of the region. Species of least concern and non-endemics are better represented in PAs than threatened and endemic species.

\section{Assessment of migratory taxa}

The most difficult species to list at the sub-global level are migratory birds. This problem has been identified by IUCN's Regional Application Working Group, but an agreed solution has not yet been achieved. The issue is the unit of assessment that should be used. If a migratory species is assessed at the sub-global level as a single unit, rather than dividing it into breeding and non-breeding populations, this risks conflating two completely separate, non-mixing populations. On the other hand, assessing these taxa as two completely separate populations risks double-counting if there is significant mixing between populations. Either extreme may give a misleading assessment of extinction risk. The approach that we took was to ignore non-breeding populations and list on the basis of the status of breeding populations only. This approach ensures that double-counting is avoided, but is not ideal because over-wintering habitat and migratory stopovers can be crucial to the survival of a population. Hence it is likely to give a biased impression of extinction risk.

The degree to which this issue is a serious problem is strongly scale-dependent. In our study, we found that listing migratory birds solely on the breeding population was less misleading at the national level because non-breeding populations were usually clearly separate from the breeding population. Hence, although the extinction risks to non-breeding populations were ignored, those for the breeding population were correctly assessed. However, at the regional level, our study area was large enough that significant overlap between the breeding and nonbreeding populations was likely for some species; hence assessing the regional population as 
a single unit would give a better reflection of extinction risk. The degree to which each of the possible assumptions about mixing is flawed is difficult to ascertain in the absence of detailed studies of movement patterns, which are not likely to be carried out for the majority of these species in the near future. Hence, although we can highlight that there is likely to be scaledependence in the degree of bias of our assessments for migratory species, solutions can be found only on a case-by-case basis.

\section{Future Directions}

Mismatches between our assessments and those reported in the 2002 IUCN Red List of Threatened Species and in national Red Data Books are most likely to be caused by a combination of the age of the data used to carry out assessments, differences in assessment criteria used, and access to different data. This is to be expected in any dynamic red listing process, and emphasises the importance of open, transparent and frequent exchange of data and expertise. Various initiatives are underway to achieve this, such as the IUCN-SSC's Species Information Service, and the fact that the Red List is now online and includes searchable databases of information justifying listings. Another important task of the IUCNSSC Red Listing Office is giving training workshops around the world, so that scientists from all regions are involved in the red listing process. Our study involved a large number of experts throughout the entire Central Asian region, and included an IUCN-led workshop on the theory and practice of red listing. The collection of data on Central Asian species served several purposes; the testing of the IUCN regional guidelines as outlined in this paper, the creation of a database of information on species at the regional and national levels for local scientists to use, and the formation of a network of scientists who can continue with joint conservation activities within the region. The next step is for the data from these activities to 
be passed on to IUCN Specialist Groups so that the global assessments for the species concerned can be updated.

\section{Conclusions}

In this study we carried out a detailed analysis of the effect of scale on threat categories, using data from 163 Central Asian species and subspecies. Generally we found that the IUCN Red List Criteria (version 3.1) performed well at the regional scale. One of the main aims of our study was to identify circumstances under which threat status appeared to be worse at a larger scale than at a smaller scale. This might indicate problems with the listing process. Lower threat statuses at smaller scales were identified in only 32 cases, involving 17 taxa. The majority of these were caused by listing at the higher level on the basis of decline rate. The rest were caused by the use of subjective criteria in the NT, VU D1 and NT categories. Our findings suggest that one of the major advantages of investing effort in carrying out regional and national threat assessments is a better understanding of the spatial structure of threatening processes. This enables conservationists to make more informed prioritisation decisions.

Our analysis of the ability of the region's protected area network to conserve threatened species was necessarily limited, due to the nature of our sample and the lack of information about PAs in the region. In particular, we did not consider variation in the level of protection actually offered by PAs. However, our preliminary results suggest there is a bias in the overall coverage of the PA network in the region, away from threatened and endemic taxa and towards game birds and mammals. This is not necessarily evidence that the needs of threatened and endemic species have been ignored. Large animals need to inhabit larger areas to maintain viable populations, are generally more wide-ranging and would be expected to 
occur in more areas. It may also be that the threats facing species with lower representation are not those that require the establishment of PAs. It is also conceivable that the presence of a disproportionate number of LC taxa inside reserves is evidence of past success of PAs in conserving the species that they do contain. Nonetheless, we raise some issues of concern here which require further attention, in particular the poor representation of endemic taxa in protected areas. 


\section{Acknowledgements}

We gratefully acknowledge funding for this work from INTAS project 99-1483. SL was funded for this work by the Leverhulme Trust and Imperial College (Beit Scientific Research Fellowship). The project involved the work of a great many specialists providing data for our assessments, to all of whom we are very grateful. Particular thanks for their contributions to this work are due to B. Abdunazarov, Ch. Ataev, R. Baydavletov, Z. Brushko, Yu. Chikin, G.Dukravetz, A. Esipov, B. Geldeev, Iu.. A. Gistsov, Yu. Grachev, D. Kashkarov, R. Kashkarov, V. Khegai, E. Khurshut, A. Khodjaev, E. Kokanova, A. Kreuzberg, J. Long, L.Marinina, I. Mityaev, Yu. Mitropolskaya, R. Muratov, N. Ogar, T. Penchukovskaya, T. Saidov, T. Salikhov, D. Saparmuradov, T. Sattarov, R.Shaymardanov, E. Shernazarov, E. Shukurov, S. Sklyarenko, L.Spivakova, T.Tokmergenov, O. Tsaruk, E. Vashetko, S. Zonshtein. The database created for this project, which contains the data used to make the assessments analysed here, is available on request from IUCN-SSC (Red List Office, redlist@ssc-uk.org ). 


\section{References}

Collar N.J., Crosby N.J. and Stattersfield A.J. 1994. Birds to Watch 2: The Birdlife International World Checklist of Birds. Birdlife International, Cambridge, UK.

Gärdenfors U., Hilton-Taylor C., Mace G.M. and Rodríguez J.P. 2001. The Application of IUCN Red List Criteria at Regional Levels. Conservation Biology 15: 1206-1212.

Gärdenfors U. 2001. Classifying threatened species at a national versus global level. Trends in Ecology and Evolution 16: 511-516.

IUCN 1994. IUCN Red List Categories, Version 2.3. IUCN Species Survival Commission, Gland, Switzerland.

IUCN 2001. IUCN Red List Categories and Criteria, Version 3.1. IUCN Species Survival Commission, Gland, Switzerland \& Cambridge, UK.

IUCN 2003. Guidelines for Application of IUCN Criteria at Regional Levels. Version 3.0. IUCN Species Survival Comission. IUCN, Gland, Switzerland and Cambridge, UK.

Jones, N. (2003) South Aral Sea "gone in 15 years". New Scientist 2404, $19^{\text {th }}$ July 2003. Available online at $\underline{w w w . n e w s c i e n t i s t . c o m / a r t i c l e . n s ? i d=d n 3947 . ~}$

Kovshar’ A.F., Bekenov A.B. and Dukravetz G.M. 1996. Red Data Book of Kazakhstan. Vol. 1. Animals. Part. 1. Vertebrates. $3^{\text {rd }}$ Edition. Konzhik, Almaty, 
Pinchera F. and Boitani L. 1997. Application to the terrestrial vertebrates of Italy of a system proposed by IUCN for a new classification of national Red List categories. Biodiversity and Conservation 6: 959-978.

Siegel S. and Castellan N.J. 1988. Nonparametric statistics for the behavioral sciences. McGraw-Hill, New York. 
Table 1 Data quality and availability for the sub-global red listing exercise.

\begin{tabular}{|c|c|c|c|c|c|}
\hline & $\begin{array}{l}\text { Number } \\
\text { assessed }\end{array}$ & $\begin{array}{c}\text { Number of } \\
\text { assessments }^{1}\end{array}$ & $\begin{array}{c}\text { Propn } \\
\text { DD }^{2}\end{array}$ & $\begin{array}{c}\text { Propn } \\
\text { globally } \\
\text { assessed }^{3}\end{array}$ & Data quality \\
\hline Mammals & 54 & 263 & 0.03 & 0.83 & $\begin{array}{l}\text { Good. Species could be } \\
\text { assessed using a variety of } \\
\text { criteria. }\end{array}$ \\
\hline Reptiles & 33 & 155 & 0.03 & 0.06 & $\begin{array}{l}\text { Very poor. Often only data } \\
\text { available was density, given } \\
\text { using a variety of units. Very } \\
\text { difficult to extrapolate. }\end{array}$ \\
\hline Fish & 13 & 67 & 0.09 & 0.46 & $\begin{array}{l}\text { Poor. Catch data often } \\
\text { available but not possible to } \\
\text { extrapolate from. }\end{array}$ \\
\hline Birds & 63 & 354 & 0.03 & 0.86 & $\begin{array}{l}\text { Very good. Population } \\
\text { estimates for breeding, } \\
\text { migratory \& wintering } \\
\text { populations often available. } \\
\text { Relatively recent data. }\end{array}$ \\
\hline
\end{tabular}

1. The total number of assessments is the product of the number of species/subspecies assessed and the number of areas of assessment (1 regional assessment + one for each of the range state countries). 
2. Proportion assessed as DD is expressed as a proportion of the total number of assessments made. $\mathrm{DD}=$ Data Deficient.

3. Proportion assessed at global level is the proportion of the taxa assessed in this study that had previously been assessed by IUCN at the global level. 
Table 2. Results of chi-squared contingency tests for predictors of the presence or absence of taxa from protected areas (PAs) ${ }^{1}$.

\begin{tabular}{|c|c|c|c|}
\hline Test & Chi-squared, df & Significance $^{2}$ & Direction \\
\hline National threat status & $37.8,5$ & $* * *$ & \\
\hline \multicolumn{4}{|l|}{ Sub-tables $^{3}$} \\
\hline $\mathrm{LC}$ vs $\mathrm{CR}+\mathrm{EN}+\mathrm{VU}+\mathrm{NT}$ & $10.37,1$ & $* *$ & $\begin{array}{l}\text { LC more represented } \\
\text { in PAs than near- \& } \\
\text { threatened taxa }\end{array}$ \\
\hline DD vs others & $17.61,1$ & $* * *$ & $\begin{array}{l}\text { DD less represented } \\
\text { in PAs than assessed } \\
\text { taxa }\end{array}$ \\
\hline Taxonomic group & {$[15.08,3]^{4}$} & $* *$ & \\
\hline \multicolumn{4}{|l|}{ Sub-tables } \\
\hline Mammals+Fish vs Reptiles & $6.64,1$ & $* *$ & $\begin{array}{l}\text { Reptiles less } \\
\text { represented in PAs }\end{array}$ \\
\hline $\begin{array}{l}\text { Mammals + Fish + Reptiles } \\
\text { vs Birds }\end{array}$ & $5.89,1$ & $*$ & $\begin{array}{l}\text { Birds more } \\
\text { represented in PAs }\end{array}$ \\
\hline Taxon commonly hunted & $4.19,1$ & $*$ & $\begin{array}{l}\text { Hunted species more } \\
\text { represented in PAs }\end{array}$ \\
\hline Habitat preference & $5.04,2$ & NS & No significant effect \\
\hline Endemicity & $20.5,2$ & $* * *$ & \\
\hline \multicolumn{4}{|l|}{ Sub-table } \\
\hline $\begin{array}{l}\text { National+Regional endemics } \\
\text { vs others }\end{array}$ & $6.06,1$ & $*$ & $\begin{array}{l}\text { Endemics less } \\
\text { represented in PAs }\end{array}$ \\
\hline
\end{tabular}


1. Species were considered to be in a PA if they were confirmed to be in at least one protected area in the region.

2. Significance is expressed as: Non-significant - NS, $\mathrm{P}<0.05-*, \mathrm{P}<0.01-* *, \mathrm{P}<0.001-$ $* * *$.

3. Where tables larger than $2 \times 2$ meet rigorous chi-square requirements and produce a significant result, the degrees of freedom are partitioned between statistically independent sub-tables to determine where the differences lie (Siegel \& Castellan 1988).

4. Where strict criteria for the application of a chi-square test were missed, but only narrowly, the results are recorded in []. 


\section{Figures}

Figure 1. A comparison of the IUCN criteria used to list species at each geographical scale. Criterion $\mathrm{A}=$ decline rate, $\mathrm{B}=$ restricted range area, which is also fragmented, declining or fluctuating, $\mathrm{C}=$ small population size which is declining and also either fragmented or fluctuating, $\mathrm{D}=$ very small population size, $\mathrm{E}=$ quantitative assessment of extinction risk.

Figure 2. A comparison of the categories under which species were listed at each geographic scale, showing a shift towards higher threat categories at smaller geographic scales. EX = Extinct, $\mathrm{RE}=$ Regionally extinct, $\mathrm{CR}=$ Critically Endangered, $\mathrm{EN}=$ Endangered, $\mathrm{VU}=$ vulnerable, NT $(\mathrm{LR} / \mathrm{nt})=$ Near-Threatened, LC $(\mathrm{LR} / \mathrm{lc})=$ Least Concern, DD $=$ Data Deficient, $\mathrm{NE}=$ Not Evaluated, NA $=$ Not Applicable. DD, NE and NA are not considered part of a hierarchy of threat status as they are categories of information availability rather than threat.

Figure 3. The effect of scale on listings, given as the percentage of assessments that changed between scales. The ordering of threat category used in this analysis is that given in Figure 2, with DD and NE/NA excluded. Three comparisons are shown; between the national and regional, national and global and regional and global listings. The "lower" bar shows cases where the degree of threat at the smaller geographical scale is assessed as lower than at the larger geographical scale, and similarly for the "equal" and "higher" bars.

Figure 4. A comparison of the number of species listed in national Red Data Books and the number assessed nationally as within the categories RE-NT in this study. KZ $=$ Kazakhstan, $\mathrm{KG}=$ Kyrgyzstan, $\mathrm{TJ}=$ Tadjikistan, $\mathrm{TM}=$ Turkmenistan, $\mathrm{UZ}=$ Uzbekistan. Data for the Red Data Book listing are from the most recent red data books, published in 1996 (KZ), 1985 (KG), 1988 (TJ), 1999 (TM) and in press (UZ). 


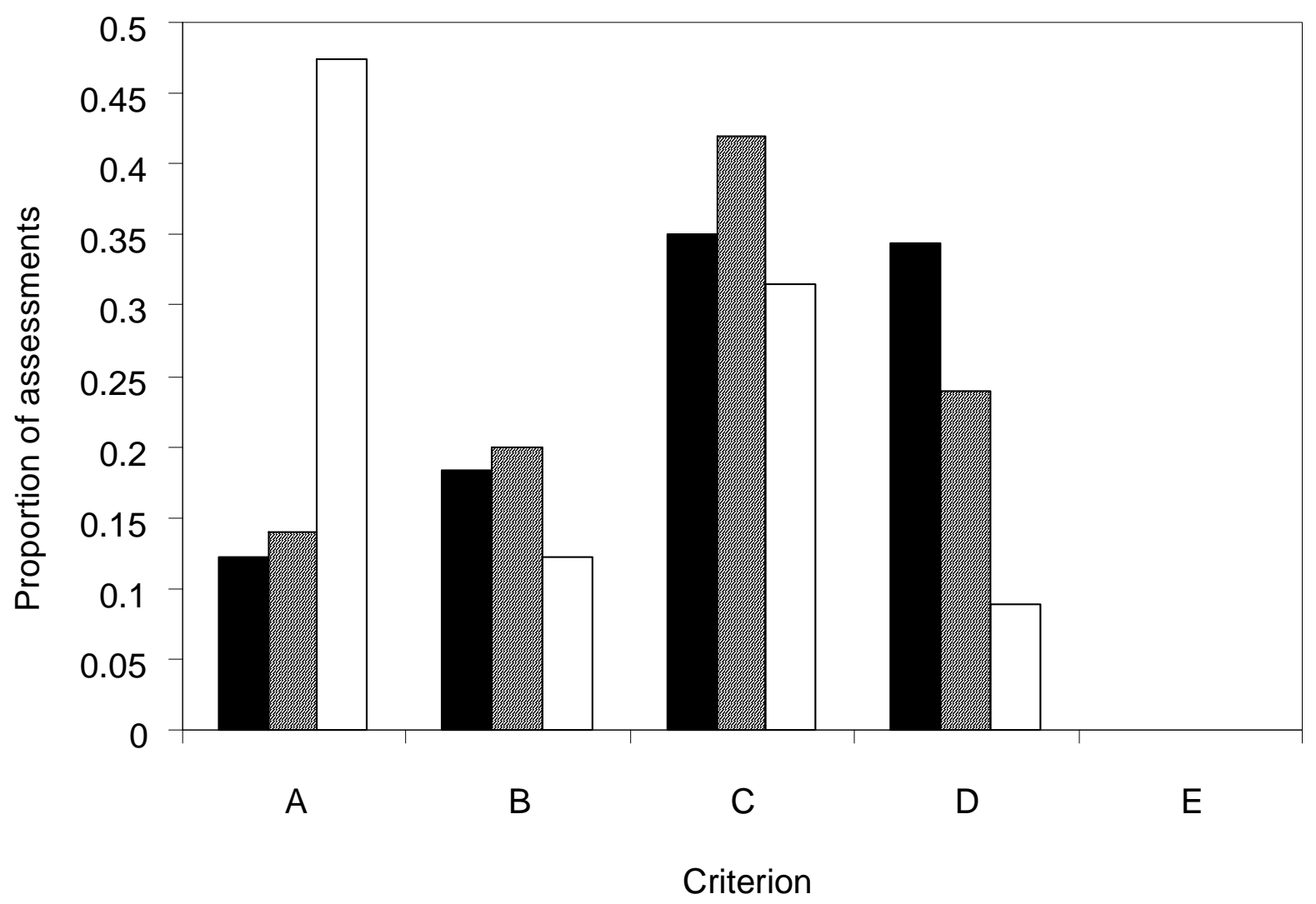

- National 国 Regional $\square$ Global 


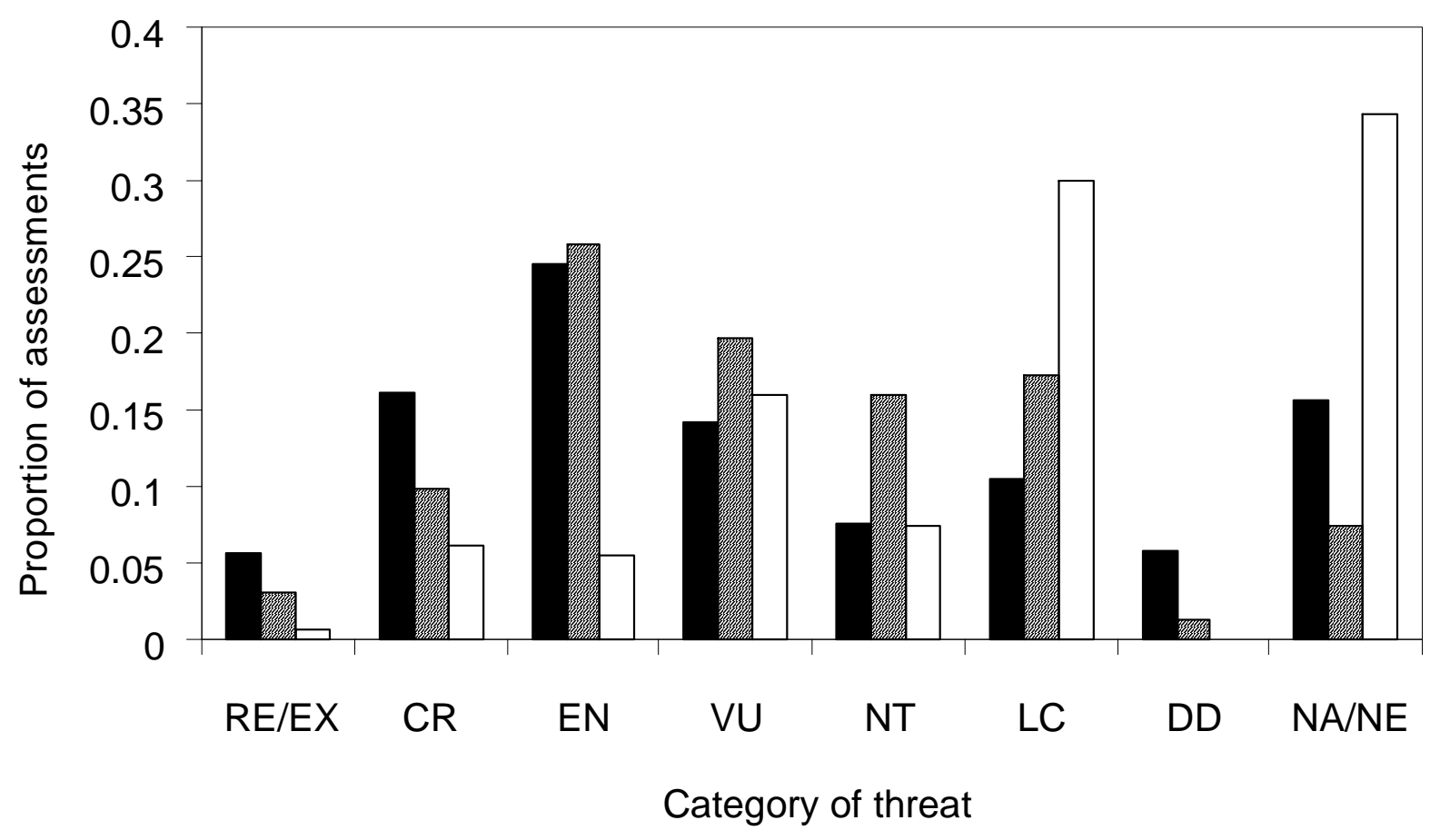

- National $\square$ Regional $\square$ Global 


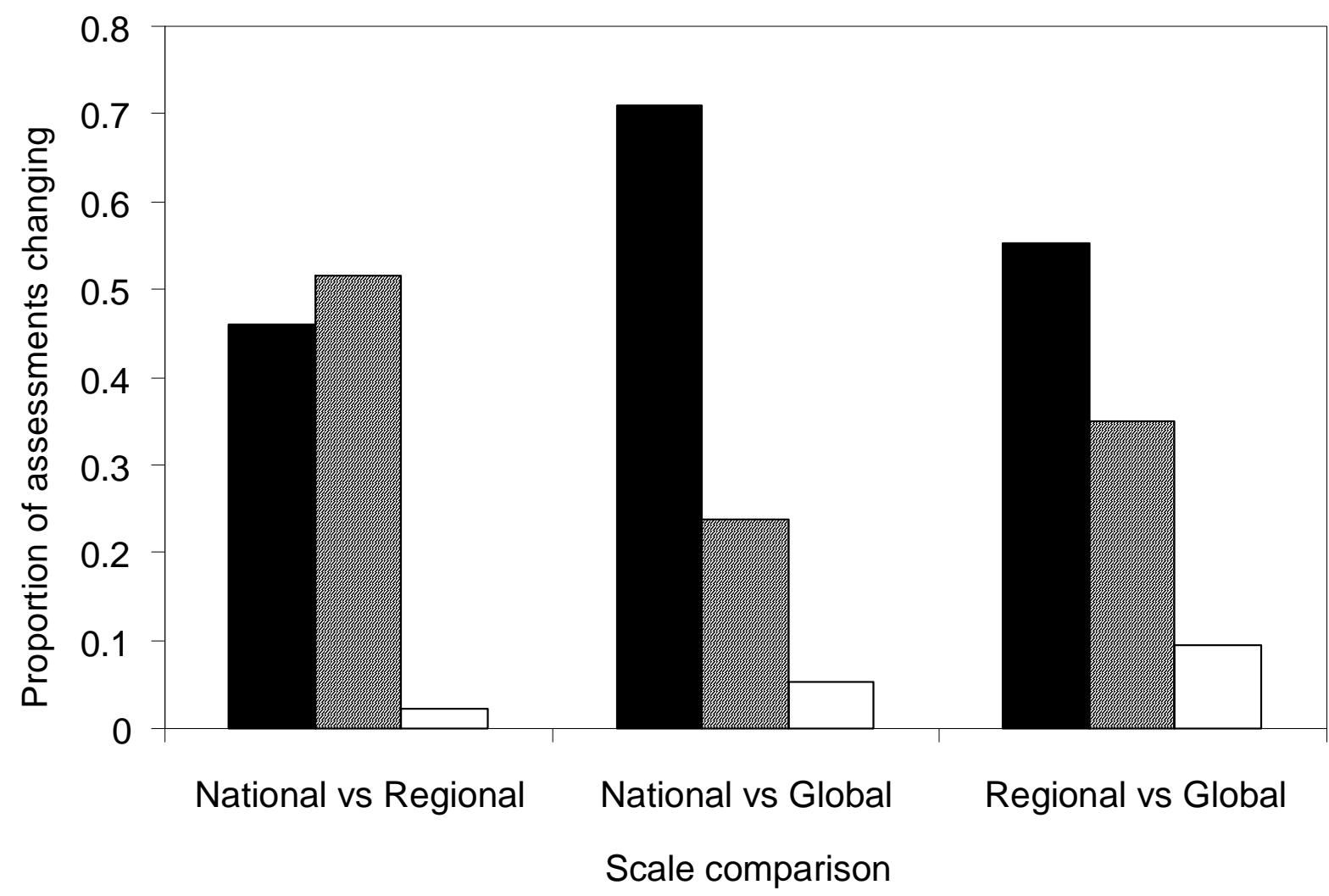

- Higher 圈 Equal $\square$ Lower 


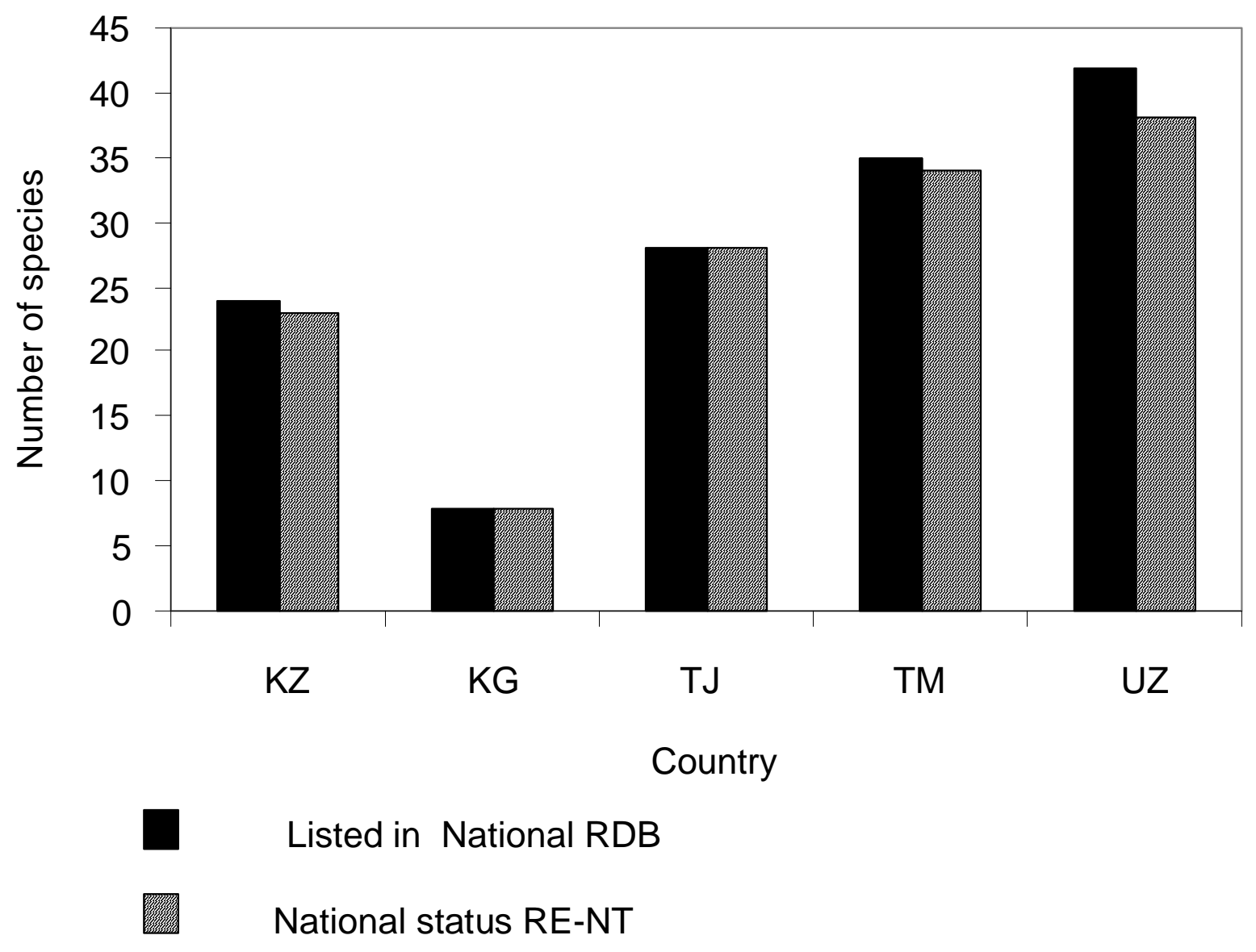

